\title{
DIAGNÓSTICO DAS PRÁTICAS DE DESCARTE DOS RESÍDUOS SÓLIDOS EM COMUNIDADES
}

\section{DIAGNOSIS OF PRACTICES IN DISPOSAL OF RESIDUES SOLID IN COMMUNITIES}

\author{
Luana Pessoa de Oliveira Araújo*E-mail: luana.pessoa@urca.br \\ Francisca Jeanne Sidrim de Figueiredo Mendonça*E-mail: jeanne.sidrim@urca.br \\ Frederico Romel Maia Tavares* E-mail: frederico.tavares@urca.br \\ Tatiane Betat Kohlrausch* E-mail: tatibetat@hotmail.com \\ Jéssica Ingrid Marinho Chaves* E-mail: jessica.ingrid@urca.br \\ *Universidade Regional Do Cariri (URCA), Juazeiro do Norte, CE
}

Resumo: Atualmente, o consumo da população seguido da produção de resíduos sólidos vem aumentando cada vez mais. A quantidade de resíduos sólidos em lixões a céu aberto prejudica à qualidade do meio ambiente, do solo e da saúde da população. Este trabalho tem como objetivo, apresentar resultados parciais do projeto, para a constituição de uma rede de coleta seletiva de resíduos sólidos. Este projeto caracteriza-se como um Estudo de Caso. Foram realizadas entrevistas estruturadas com uso de um questionário feito através da ferramenta google forms para a coleta de dados. Concluiu-se a partir dos resultados obtidos que, a comunidade desconhece a importância do descarte adequado dos resíduos sólidos e a separação de lixo, assim como uma possível reciclagem ou reuso. Neste caso, ações mínimas como a realização de cursos relacionados à educação ambiental, saúde, economia e empreendedorismo podem ser aplicadas as comunidades como forma de melhorar a qualidade de vida, gerar renda e contribuir com a sustentabilidade.

Palavras-chave: Logística reversa. Coleta seletiva. Resíduos. Desenvolvimento sustentável. Educação ambiental.

\begin{abstract}
Currently, the population's consumption followed by the production of solid waste has been increasing more and more. The amount of solid waste in open-air dumps affects the quality of the environment, the soil and the health of the population. This work has as objective, to present partial results of the project, for the constitution of a network of selective collection of solid residues. This project is characterized as a Case Study. Structured interviews were conducted using a questionnaire made using the google forms tool for data collection. It was concluded from the results obtained that the community is unaware of the importance of proper disposal of solid waste and garbage separation, as well as a possible recycling or reuse. In this case, minimal actions such as courses related to environmental education, health, economics and entrepreneurship can be applied to communities as a way to improve the quality of life, generate income and contribute to sustainability.
\end{abstract}

Keywords: Reverse logistic. Selective collect. Residues. Sustainable development. Environmental education. 


\section{INTRODUÇÃO}

Atualmente, o consumo da população seguido da produção de resíduos sólidos aumenta em progressão geométrica. A quantidade de resíduos depositado em lixões a céu aberto causa prejuízo à qualidade do meio ambiente, do solo e da saúde da população. Diante de ações do descarte inadequado de resíduos sólidos, vem sendo observado à necessidade da aplicação da Logística Reversa (LR) a partir da implantação de ações sistemáticas para o retorno do resíduo ao processo produtivo.

A prática da logística reversa traz muitos benefícios para o ambiente, à sociedade e para as empresas, pois tem o foco no retorno de materiais que já foram utilizados no processo produtivo a fim de se realizar o reaproveitamento, reutilização e reciclagem de produtos, diminuindo o desperdício de insumos.

Guarnieri (2011 apud SCHUINSEKEL et al., 2017, p.4 ) "afirma que a adoção da logística reversa permite diminuir o desperdício e a poluição com relação aos materiais de embalagens". Conforme Schuinsekel et al (2017) aplicando novas técnicas de reciclagem e reutilização, as empresas irão preservar cada vez mais o ambiente e consequentemente proporcionarão um ganho enorme para a sociedade.

O objetivo da coleta seletiva é separar os resíduos sólidos a fim de reduzir o volume de lixo que é depositado de forma incorreta e encaminhá-los para o destino final adequado, podendo ser reciclados e transformados em novos produtos. Com o gerenciamento dos resíduos é possível alcançar às metas contidas nos objetivos de Desenvolvimento Sustentável da agenda 2030 (ODS).

A coleta seletiva pode ser definida a partir da triagem dos resíduos sólidos que podem ser reciclados e classificados de acordo com sua origem, como por exemplo, os papeis, plásticos, vidros e metais. "O objetivo maior da coleta seletiva é reduzir o volume de lixo e gerar ganhos ambientais, é um investimento no meio ambiente e na qualidade de vida" (SOUZA, 2015, p.7). Ainda segundo Souza; Melo (2015, p.7), "a coleta seletiva é uma alternativa para o melhor reaproveitamento do lixo, papel, vidro, metal plástico e matéria orgânica."

Nesse contexto, o presente trabalho tem como objetivo apresentar os resultados parciais do projeto para constituição de uma rede de coleta seletiva para resíduos sólidos, com o intuito de apoiar a implantação de associações e/ou 
cooperativas de catadores em comunidades. $\mathrm{O}$ estudo de caso foi realizado no entorno geográfico dos Geositios do Geopark Araripe.

A questão de pesquisa reside no fato de conhecer e contribuir com a pesquisa acadêmica e com elementos da economia criativa, pergunta-se, portanto: A comunidade, objeto do estudo, possui potencial para a formação de uma associação e ou cooperativa que garanta a sustentabilidade diante da sua realidade e dos esforços de capacitação das IES locais?

\title{
2 FUNDAMENTAÇÃO TEÓRICA
}

\subsection{Descartes de resíduos sólido}

O artigo 3ํㅡ, inciso XVI da Lei 12.305/2010 define o conceito de resíduos sólidos como:

\begin{abstract}
XVI - resíduos sólidos: material, substância, objeto ou bem descartado resultante de atividades humanas em sociedade, a cuja destinação final se procede, se propõe proceder ou se está obrigado a proceder, nos estados sólido ou semissólido, bem como gases contidos em recipientes e líquidos cujas particularidades tornem inviável o seu lançamento na rede pública de esgotos ou em corpos d'água, ou exijam para isso soluções técnica ou economicamente inviáveis em face da melhor tecnologia disponível (BRASIL, 2010, Art. 3).
\end{abstract}

Os resíduos sólidos gerados pela população devem ter uma destinação ambientalmente correta. Quando um resíduo é descartado não significa dizer que ele não tem mais valor, porém, para a pessoa que fez o descarte, esse resíduo não tem mais utilidade. Muitas vezes esse resíduo pode ser útil para outra pessoa, por meio de uma reciclagem ou reutilização.

O descarte incorreto dos resíduos sólidos é um grande problema, pois além de prejudicar a saúde humana, contamina também o meio ambiente. Portanto, existem outros destinos para estes resíduos, bem como: a reciclagem, a compostagem, a reutilização, a coleta seletiva, os aterros sanitários e até mesmo conscientização das pessoas, todas essas são maneiras corretas de destinar os resíduos.

"A quantidade de resíduos sólidos urbanos destinados inadequadamente no Brasil cresceu $16 \%$ na última década. O montante passou de 25,3 milhões de 
toneladas por ano em 2010 para 29,4 milhões de toneladas por ano em 2019" (AGÊNCIA BRASIL, 2020)

O descarte incorreto de lixo há anos vem mostrando o quão prejudicial pode ser, causando doenças e prejuízos expressivos, tanto ecológico quanto social. Segundo a Retec Resíduos (2019), o Índice de Sustentabilidade da Limpeza Urbana (Selur) indica que $24 \%$ dos brasileiros não fazem a coleta de lixo, isso ocorre principalmente devido à falta de informação em relação aos danos que o descarte incorreto pode causar a saúde e ao meio ambiente. Dessa forma, o governo e as entidades de saneamento tanto públicas quanto privadas, precisam desenvolver métodos que viabilizem e eduquem no destino correto dos resíduos.

Ainda segundo a Retec Resíduos (2019):

\begin{abstract}
"o Sul é a região brasileira onde melhor se depositam os resíduos do ponto de vista ambiental: $88,5 \%$ do lixo é destinado de maneira correta. O Sudeste fica em segundo lugar, com $51,1 \%$ de destinação correta dos resíduos. No Norte e no Centro-Oeste, a taxa de descarte adequado é de, respectivamente, $14,1 \%$ e $14,4 \%$. A região Nordeste do país conta com um índice de 11,4\%" (RETEC RESIDUOS, 2019).
\end{abstract}

Segundo a BRK Ambiental (2021), de acordo com dados da Associação Brasileira de Empresas de Limpeza Pública e Resíduos Especiais (Abrelpe), é possível reciclar 30\% de todo lixo produzido no Brasil, mas apenas 3\% é reaproveitado, consequentemente perdendo lucro por não aproveitar oportunidades de viabilidade econômica com o descarte feito de forma correta, pois muitas famílias, por exemplo, poderiam ter uma renda através da reciclagem.

Nesse sentido, há alguns métodos de como deve ser feita a reutilização, através das seguintes opções:

- Reciclagem: trata-se da reintrodução dos resíduos no processo de produção;

- Compostagem: processo biológico de decomposição da matéria orgânica contida em restos de origem vegetal ou animal. É considerada um tipo de reciclagem de lixo orgânico;

- Geração de energia térmica: é o processo de incineração através da queima de resíduos;

- Fabricação de adubos orgânicos: reaproveitamento de materiais vindos da indústria ou da propriedade rural e reutilização do lixo orgânico caseiro. 
Para a realização dessas atividades é essencial o trabalho dos catadores, onde quase todos os resíduos que são reciclados no país trata-se dos resultados obtidos nesses serviços. Essas práticas podem ser realizadas junto a alguns parceiros que permitem a retirada desses rejeitos ou por meio da procura dos materiais recicláveis nas ruas ou lixões.

A função do catador traz um grande benefício a companhia responsável pela limpeza urbana, pois reduz radicalmente seus custos de operação já que os milhões de resíduos coletados pelos catadores deixam de ser alocados nos aterros sanitários, aumentando a vida útil desses sistemas e contribuindo com o meio ambiente.

Portanto, através de uma pesquisa feita pela BRK Ambiental, uma das primeiras empresas privadas de saneamento básico no Brasil, essas são as medidas necessárias que poderiam tornar o descarte do lixo mais adequado no país: evitar o desperdício de alimentos; incentivar o consumo sustentável; reforçar as políticas de logística reversa; estimular a diminuição da geração de resíduos; fiscalizar de forma mais eficiente os aterros sanitários; apoiar as cooperativas e associações de catadores de lixo; ampliar o apoio governamental às cooperativas de reciclagem; priorizar o descarte de lixo em locais com lixeiras apropriadas; priorizar o encerramento das atividades nos lixões a céu aberto; incentivar o tratamento adequado e a seleção dos lixos domésticos; tornar a necessidade do saneamento básico uma causa para a sociedade; promover o estímulo contínuo à reciclagem e à reutilização dos resíduos; desenvolver novas ferramentas tecnológicas específicas para essa área; promover campanhas para práticas de compostagem residencial e industrial; evitar jogar restos de alimentos ou quaisquer tipos de lixos em vias públicas; evitar a aquisição de produtos descartáveis, principalmente de papel e de plástico; instituir campanhas de educação continuada sobre educação ambiental nas escolas; priorizar a organização e o planejamento para comprar somente o que for útil e necessário; aumentar os incentivos fiscais às empresas privadas que promoverem práticas inovadoras; colocar duas lixeiras na cozinha: utilizar uma para o lixo orgânico e outra para os dejetos recicláveis; promover o descarte dos itens eletrônicos e de materiais volumosos de modo mais consciente; criar o hábito de utilizar sacola retornável e evitar levar mais embalagens ou sacolas de plástico para casa. 
O Quadro 2 apresenta algumas experiências com destino de resíduos sólidos em outros países e as oportunidades econômicas e sociais através de ações de melhoria. Sendo assim, essa atividade gera economia para os cofres dos órgãos responsáveis pelo manejo do lixo, além do mais importante, a reciclagem realizada pelos catadores possibilita a reutilização de diversos materiais e evita o consumo de novas matérias-primas.

Quadro 2 - Experiências com destino de resíduos sólidos em outros países

\begin{tabular}{|c|c|c|c|c|}
\hline Oportunidades & Ações em outros locais & Local & Resultados & Referência \\
\hline \multirow{3}{*}{$\begin{array}{l}\text { Potencial turístico } \\
\text { ambiental, científico e } \\
\text { cultural }\end{array}$} & \multirow{3}{*}{$\begin{array}{l}\text { Conscientização, com ações de visíveis } \\
\text { reduções dos resíduos produzidos pela } \\
\text { atividade turística no litoral. }\end{array}$} & \multirow{3}{*}{ Vietnã } & Observou-se incremento da atividade turística. & \multirow{3}{*}{ Tsai et al. (2021) } \\
\hline & & & $\begin{array}{l}\text { Os empreendimentos criaram um fundo e juntamente com } \\
\text { o apoio da população desenvolveram a redução dos } \\
\text { resíduos, criando oportunidade de geração de renda. }\end{array}$ & \\
\hline & & & $\begin{array}{l}\text { Índices mostram eficácia na competitividade da cidade que } \\
\text { podem aumentar com um planejamento. }\end{array}$ & \\
\hline \multirow{2}{*}{ Geração de renda } & $\begin{array}{l}\text { Criar indicadores de sustentabilidade para um } \\
\text { melhor planejamento de ações para gestão de } \\
\text { um negócio. }\end{array}$ & $\begin{array}{c}\text { Brasil } \\
\text { (Sergipe) }\end{array}$ & Incremento na economia circular. & $\begin{array}{c}\text { Faxina, } \\
\text { Freitas e Travisan } \\
\text { (2021) }\end{array}$ \\
\hline & $\begin{array}{l}\text { Orientação aos habitantes e turistas, da } \\
\text { importância de práticas sustentáveis no meio } \\
\text { ambiente. }\end{array}$ & Ilhas Canárias & $\begin{array}{l}\text { Aumento de renda da população local e maior atratividade } \\
\text { turística. }\end{array}$ & $\begin{array}{l}\text { Rodriguez, } \\
\text { Jacob e Florindo } \\
(2020)\end{array}$ \\
\hline $\begin{array}{l}\text { Melhoria da Qualidade de } \\
\text { vida }\end{array}$ & $\begin{array}{l}\text { Ações das empresas de mineração na } \\
\text { destinação correta dos rejeitos gerados. }\end{array}$ & $\begin{array}{c}\text { Croácia } \\
\text { (llhas Brac) }\end{array}$ & $\begin{array}{l}\text { Engajamento da comunidade, investimento das empresas } \\
\text { e a possibilidade da Croácia a ingressar em } 2030 \text { na união } \\
\text { europeia. }\end{array}$ & Margeta (2021) \\
\hline Desenvolvimento regional & $\begin{array}{l}\text { Resíduos gerados podem ser melhor } \\
\text { reaproveitados. }\end{array}$ & China (Lhasa) & & $\begin{array}{c}\text { Wang et al. } \\
(2021)\end{array}$ \\
\hline
\end{tabular}

Fonte: Os autores (2021)

\subsection{Gestão de Resíduos Sólidos}

A gestão correta dos resíduos sólidos em comunidades tem o objetivo de diminuir o impacto negativo no meio ambiente, melhorar a saúde humana e a imagem do local. O acúmulo de resíduos sem nenhum tratamento também atrai animais responsáveis pela transmissão de doenças que podem afetar o meio ambiente e a saúde humana (LUTINSKI et al., 2017).

Segundo a VG Resíduos (2020), a gestão de resíduos pode ser definida pela realização de um conjunto de ações adequadas nas etapas de coleta, armazenamento, transporte, tratamento, destinação final e disposição final ambientalmente aceita, com o objetivo de minimizar da produção de resíduos, visando à preservação da saúde pública e a qualidade do meio ambiente.

A má gestão dos resíduos sólidos causa graves impactos ambientais e danos à saúde humana. Os impactos causados pela má gestão dos resíduos sólidos, 
segundo a VG Resíduos (2020) causam poluição atmosférica, poluição hídrica, poluição do solo e poluição visual, e, além disso, dependendo do tipo de resíduos, podem causar doenças para população, ocasionando o dano a saúde das pessoas.

Segundo o presidente da ABRELPE, "falta ao brasileiro a educação ambiental e consciência de que o resíduo sólido precisa ser visto como um recurso para um processo futuro, por meio da reciclagem" (REVISTA BRASIL, 2021).

Uma gestão de resíduos adequada traz grandes vantagens para todos nas comunidades. Algumas dessas vantagens são: contribuição para a limpeza do local, melhoria no ambiente e na imagem do local, redução do impacto ambiental e redução da proliferação de animais advindos do manejo inadequado destes resíduos.

\subsection{Coleta Seletiva}

A coleta seletiva pode ser definida como um método de recolhimento de resíduos que podem ser reciclados. Esse processo é feito por meio da separação dos resíduos de acordo com os tipos de cada um, a fim de evitar a contaminação dos materiais reaproveitáveis, aumentando o valor agregado destes e diminuindo os custos de reciclagem. A reciclagem é considerada uma ação de extrema importância na vida moderna devido um aumento do consumismo e uma diminuição do tempo médio de vida.

"A coleta seletiva é uma atividade que tem atraído grande interesse da sociedade, tanto pela sua contribuição à sustentabilidade urbana como pela geração de renda, de cidadania e pela economia de recursos naturais que proporciona." (CONKE; NASCIMENTO, 2018)

A coleta seletiva realizada corretamente evita a disseminação de doenças e contribui para que os resíduos se encaminhem para o descarte correto. Separar os resíduos entre plástico, metal, papel e orgânicos contribui também para acabar com poluições tóxicas que contaminam solos e águas de rios, e que trazem prejuízos à saúde humana.

"O primeiro passo da coleta seletiva diz respeito à realização de campanhas informativas de conscientização junto à população, convencendo-a da importância da reciclagem e orientando-a para que separe os resíduos" (RIBEIRO, 2017, p.3). 
Segundo Bravo, Penhaça, Werner e Santos (2018), uma das formas para diminuir a quantidade excessiva de lixo nos depósitos e ainda colaborar para a sustentabilidade urbana, é o estabelecimento da coleta seletiva de resíduos recicláveis. A Lei Federal 12.305/2010 da Política Nacional de Resíduos Sólidos (PNRS) do Brasil denomina uma referência que certifica a gestão integrada e sustentável de resíduos sólidos no país. Além disso, apresentou metas para o estabelecimento e aperfeiçoamento da coleta seletiva nos municípios brasileiros.

De acordo com a Koleta Ambiental (2019), uma empresa que está atuando há 18 anos nas duas maiores capitais do país prestando serviço de coleta, transporte, destinação e reciclagem de resíduos para garantir a preservação do meio ambiente, a principal função das cores das latas de lixo é promover a fácil memorização por parte das pessoas.

O despejo do lixo na lata de recolhimento correta tem bastante importância, pois se despejado de forma inadequada, todo o processo de reciclagem pode ser comprometido. Desta forma, irá proporcionar facilidade no trabalho dos catadores.

Ainda segundo a Koleta Ambiental (2019), as cores das latas de lixo são assim descritas:

- Lata de lixo azul - Papel e papelão;

- Lata de lixo vermelha - Plástico;

- Lata de lixo verde - Vidro;

- Lata de lixo amarela - Metal.

Geralmente, a maioria dos lugares públicos apresentam apenas estas 4 cores de latas citadas a cima, mas o Conselho Nacional do Meio Ambiente (CONAMA) aponta que existem 10 tipos diferentes de resíduos sólidos, ou seja, dez cores de lata. Por tanto, as demais latas são:

- Preto - madeira;

- Laranja - resíduos sólidos;

- Branco - resíduos ambulatoriais e de serviços de saúde;

- Roxo - resíduos radioativos;

- Marrom - resíduos orgânicos;

- Cinza - resíduos gerais não reciclável ou misturado, ou contaminado não passível de separação. 


\title{
2.4 Logística Reversa
}

A logística reversa pode ser caracterizada por um conjunto de ações, procedimentos e meios destinados a fim de facilitar a coleta e a restituição dos resíduos sólidos e com isso: "A logística reversa (LR) trata do manejo e do retorno destes descartes ao ponto de origem ou aos canais reversos de redistribuição" (BARBOZA et al., 2015, p.2).

A logística reversa é uma ferramenta que une a gestão de processos e o descarte correto de inúmeras categorias de materiais, evitando o desperdício e uma possível degradação do material na natureza, fazendo a junção de sustentabilidade e produção (SILVA et al., 2019).

O artigo $3^{\circ}$, inciso XII da Lei 12.305/2010 define o conceito de logística reversa como:

\begin{abstract}
XII - logística reversa: instrumento de desenvolvimento econômico e social caracterizado por um conjunto de ações, procedimentos e meios destinados a viabilizar a coleta e a restituição dos resíduos sólidos ao setor empresarial, para reaproveitamento, em seu ciclo ou em outros ciclos produtivos, ou outra destinação final ambientalmente adequada (BRASIL, 2010, Art. 3).
\end{abstract}

A logística reversa trata a recuperação de produtos, embalagens, ou outros materiais, desde o ponto de consumo até a origem de forma mais sustentável possível. "Com o objetivo de reduzir o volume de resíduos sólidos, atualmente descartados, mas com potencial para reciclagem, foram concebidos diversos métodos, dentre os quais se destaca a logística reversa" (MENDES et al., 2016, p.3).

"Podemos definir resíduos como sendo todo material proveniente de atividades humanas nas indústrias, comércios e residências que seja considerado inútil. Neste conceito, o termo lixo, está incluído sob as diversas formas, inclusive o lixo tóxico e prejudicial ao meio ambiente" (GARCIA et al., 2015, p.3). Os resíduos sólidos também podem ser entendidos por aqueles materiais sem utilidade, que chegaram ao fim de sua vida útil e que devem ser descartados ou eliminados.

"A coleta seletiva, a reciclagem e o reuso de materiais, são esforços usados para diminuir a produção de lixo" (SOUZA; MELO, 2015, p.5). A partir da coleta seletiva e o gerenciamento adequado dos resíduos, é possível que seja alcançado às metas contidas nos objetivos de Desenvolvimento Sustentável (ODS). 
"A proposta dos ODS não é "reinventar a roda". É utilizá-los para facilitar o desenvolvimento de ações integradas, com uma visão de futuro positiva e comum a diferentes grupos, que gere impactos reais na construção do desenvolvimento sustentável" (CNM, 2020).

"O ODS \#08 está relacionado à promoção de políticas que incentivem o empreendedorismo e a criação de empregos de forma sustentável e inclusiva" (BELLEN; PETRASSI, 2017, p.8).

"A logística da gestão de resíduos sólidos urbanos é complexa e envolve muitos setores e atores gerando também inúmeras oportunidades de novos negócios e empregos" (BELLEN; PETRASSI, 2017, p.8).

"Transformar significativamente a construção e a gestão dos espaços urbanos é essencial para que o desenvolvimento sustentável seja alcançado segundo o ODS \#11" (BELLEN; PETRASSI, 2017, p.9).

Sabe-se que o destino inadequado dos resíduos pode causar grandes impactos ao clima. As ações contra a mudança global do clima constituem o objetivo 13 da ODS. Segundo a AGENCIA 2030, uma das metas da ODS 13 é "Melhorar a educação, aumentar a conscientização e a capacidade humana e institucional sobre mitigação global do clima, adaptação, redução de impacto, e alerta precoce à mudança do clima" (AGENDA 2030, 2020).

\subsection{Aplicações da Logística Reversa}

Em 2010, uma lei foi criada para que setores com fabricantes e comerciantes de determinados tipos de produtos aderissem a logística reversa. Algumas empresas adotam outros relacionados a estes assuntos, mas existem outras que são obrigadas devido seus produtos causarem risco ao meio ambiente.

A adoção da prática da logística reversa é de extrema importância para qualquer empresa. As empresas que adotam essa prática estão alcançando a sustentabilidade econômica e ambiental do seu negócio, pois além de contribuir para a preservação e diminuição da poluição do meio ambiente, traz vários benefícios para as empresas, como por exemplo: Melhoria da imagem da empresa; Benefícios 
econômicos gerando economia com o reaproveitamento de materiais; Geração de novas oportunidades de negócios; Melhoria dos processos produtivos, entre outros.

Várias companhias aderem projetos e ações voltados a logística reversa tanto para seus próprios produtos, quanto para arrecadar matéria-prima para desenvolvimento de novos produtos.

Alguns exemplos dessas empresas são:

- A Bridgestone destina seus resíduos para aplicação diversa, inclusive como substituto da brita em obras.

- A Natura, empresa nacional de cosméticos, criou um programa que recolhe as embalagens vazias dos seus produtos, após o uso, evitando que sejam descartados na natureza.

- A Unilever vai se concentrar na redução dos gases de efeito estufa, pois os produtos de lavanderia, como o shampoo, são geralmente utilizados com água quente, desta forma, consumindo muita energia; no melhor aproveitamento da água, devido à necessidade de as pessoas terem de usar em quase todos os produtos da marca; e no tratamento dos resíduos, pelo fato de serem compradas toneladas de embalagem por ano.

- A Nestlé busca sempre encontrar alguma alternativa para reaproveitar os resíduos gerados nas fábricas, seja reutilizando-os na produção, seja destinando-os a parceiros. No Brasil, já se atingiu a marca de zero resíduo em cinco fábricas.

- A Samsung possui o slogan "Planet First" que expressa o compromisso em proteção ao meio ambiente. Desta forma, a empresa utiliza a policetona, um material que contribui para a redução do monóxido de carbono (gás de efeito estufa) nos seus smartphones e tablets Galaxy desde 2016.

A logística reversa é importante não só para o meio ambiente, mas também para empresa, dando-lhe uma boa imagem, conquistando o público exigente e obtendo um diferencial competitivo. Pode ser aplicada em todos os tipos de companhias independentemente do tamanho mesmo sendo obrigatório apenas nos setores que lidam com produtos prejudiciais. 


\section{METODOLOGIA}

Este projeto, em seu método inicial caracteriza-se como um Estudo de Caso. Estudo de caso consiste em uma estratégia de pesquisa que permite ao pesquisador "considerar as características holísticas e significativas dos eventos da vida real" (YIN, 2015, p.2).

Segundo Yin (2015), "O estudo de caso é usado em muitas situações, para contribuir ao nosso conhecimento dos fenômenos individuais, grupais, organizacionais sociais, políticos e relacionados".

A presente pesquisa é classificada como exploratória, envolvendo levantamento de literatura e entrevistas estruturadas em comunidades localizadas nos geossítios no entorno geográfico do Geopark Araripe.

Segundo Yin (2015), a entrevista pode ser considerada como uma das mais importantes fontes de informação dentro de um estudo de caso. Ainda segundo o autor, é comum que as entrevistas que são realizadas nos estudos de caso, sejam conduzidas de forma espontânea, isso porque o entrevistador pode tentar indagar o respondente quanto a solicitar a opinião dele sobre o assunto em questão.

As visitas ocorreram em cinco comunidades: Comunidade Pedra Branca no geossítio Pedra Cariri, Comunidade Sítio Olho D'água de Santa Bárbara e Comunidade Sítio Gostoso no geossítio Ponte de Pedra, todas localizadas na cidade de Nova Olinda; Comunidade Sertãozinho no geossítio Batateiras na cidade do Crato; e a Comunidade Caldas do geossítio Riacho do meio, localizada na cidade de Barbalha.

O território do Araripe Geopark mundial da UNESCO abrange os municípios do Crato, Juazeiro do Norte, Barbalha, Missão Velha, Nova Olinda e Santana do Cariri, dotados de nove geossítios: Batateiras, Colina do Horto, Riacho do Meio, Cachoeira de Missão Velha, Floresta Petrificada, Ponte de Pedra, Pedra Cariri, Pontal de Santa Cruz e Parque dos Pterossauros. A Figura 1 mostra o mapa da localização dos geossítios. 
Figura 1 - Mapa da localização dos geossítios

ARARIPE GEOPARQUE MUNDIAL DA UNESCO / ARARIPE UNESCO GLOBAL GEOPARK

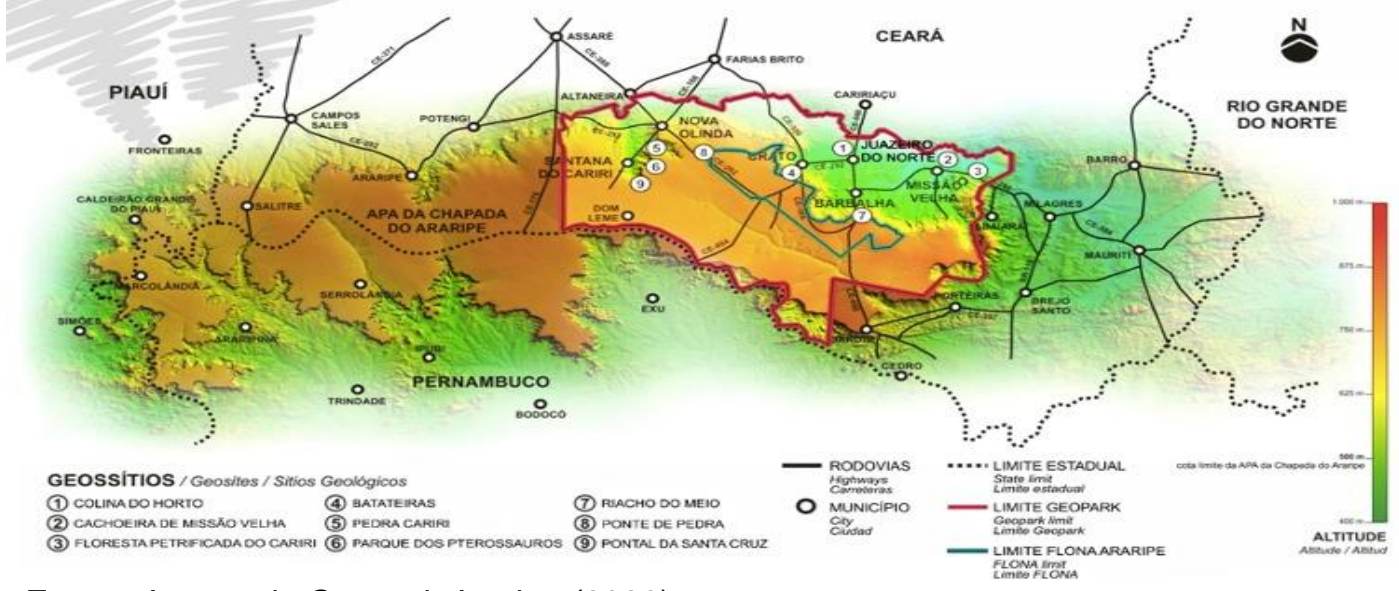

Fonte: Acervo do Geopark Araripe (2020)

Nesse sentido, por meio das visitas às comunidades e com a posterior definição de respondentes, foram realizadas entrevistas estruturadas com uso de um questionário feito através da ferramenta google forms para a coleta de dados visando alcance dos objetivos dessa pesquisa. Também foi possível verificar aspectos relevantes, possibilitando uma análise consistente, garantindo assim maior credibilidade aos resultados e conclusões, os quais serão apresentados na sequência desse estudo.

Os dados foram obtidos através de questionário aplicado a 80 habitantes, maiores de 18 anos, utilizando a ferramenta DataScope. Estas informações foram colhidas em entrevistas realizadas em 10 visitas nas comunidades. As perguntas que compunham o questionário eram as seguintes:

1. Quantas pessoas moram em sua residência contando com você?

2. Quantos quartos há em sua casa?

3. Você trabalha?

4. Conhece alguém que tem horta comunitária?

5. Se sim, quantas?

6. Tem acompanhamento médico para as pessoas da comunidade?

7. Você observa a existência de algum programa na comunidade voltado para questões ambientais?

8. A sua residência possui água encanada? 
9. Existe algum problema na distribuição de água?

10. Já participou de alguma oficina para a criação de artesanatos ou produtos caseiros?

11. Você teria algum interesse em investir no desenvolvimento de artesanatos ou produtos caseiros?

12. De 1 a 5 , você considera a venda desses produtos importante para 0 crescimento econômico da comunidade?

13. Você acha que a venda desses produtos influencia o turismo da região?

14. Os turistas do Geossítio vêm até a comunidade?

15. Se "sim" quantos turistas em média por semana?

16. Quais impactos na comunidade deixados pelos turistas?

17. Existe atividade econômica na comunidade ligada ao geossítio?

18. Caso a resposta anterior tenha sido "sim ", quais são?

19. O Geossítio traz alguma rentabilidade para a comunidade?

20 . Você tem conhecimento sobre reciclagem?

21. Existe algum tipo de reciclagem dos resíduos na comunidade?

22. Você conhece alguém na comunidade que trabalha com reciclagem, ou é catador?

23. Os artesanatos ou produtos caseiros são uma boa representação da cultura e religião da comunidade?

24. $\mathrm{Na}$ comunidade existe alguma ação para a redução do consumo de energia?

25. De 0 a 5 defina sua participação nessas ações.

26. Você faz a separação dos lixos da sua casa?

27. Se sua resposta foi "sim", como você faz essa separação? Segue alguma norma?

28. Na sua casa já teve algum caso de doença causado pelo acúmulo de lixo na comunidade?

29. O caminhão do lixo passa na comunidade fazendo a coleta do lixo?

30. Se sua resposta foi "sim" na resposta anterior, quantas vezes na semana ocorre a coleta? 
31. Nesta comunidade, o acúmulo de lixo costuma causar entupimento nas redes e canais de esgoto?

32. Há algum rio nas proximidades da comunidade?

33. Se a resposta anterior foi "sim", sabe-se que a obstrução do leito de rios é causada pelo lançamento de lixo da população que vive próxima das margens, consequentemente causando inundação em épocas de chuvas, nesta comunidade, isto (inundação) ocorre nesses períodos chuvosos?

34. Você observou um aumento de insetos e roedores?

35. Há caçambas de lixo nas ruas desta comunidade?

36. Há caçambas de lixo nas ruas desta comunidade?

37. Foi notado queima constante de lixo nestas proximidades?

As respostas fornecidas pelos entrevistados foram estudadas a fim de identificar as necessidades de cada comunidade e os pontos que precisam ser trabalhados para o alcance da sustentabilidade nos geossítios em questão.

\section{RESULTADOS}

Com o resultado das respostas dos questionários aplicados aos moradores das comunidades, pode-se perceber que a maioria dos entrevistados não fazem a separação do lixo e não entendem a importância dessa separação e do descarte correto dos resíduos, tanto para os próprios moradores quanto para o meio ambiente. Todas as comunidades dispõem de caminhões de lixo fazendo a coleta pelo menos uma vez na semana, porém os residentes destas relataram não possuir caçambas de lixo nas localidades.

Durante a visita na comunidade do Caldas localizada no Município de Barbalha no Estado do Ceará, foi observado que a maioria das pessoas entrevistadas desconhecem a existência de programas na comunidade voltados para questões ambientais, mas têm o conhecimento sobre reciclagem e atestam que na comunidade tem pessoas que trabalham com a reciclagem: um catador e um empresário que organizou uma coleta seletiva com alguns moradores e compra deles os resíduos classificados. 
Na visita à comunidade Pedra Branca, localizada no município de Nova Olinda, foi relatado pelos moradores que esta recebe muitos turistas e que o maior impacto observado é o lixo deixado por estes visitantes. Não foi observado nenhum ponto de reciclagem e segundo os entrevistados não há pessoas que trabalhem com resíduos ou catadores na comunidade. Inexistem caçambas de lixo nas ruas e qualquer orientação com relação à classificação e separação de lixo. Em uma igual quantidade de respostas, as pessoas afirmam e negam a existência de queima de lixo frequente na região.

$\mathrm{Na}$ visita à comunidade do Sitio Gostoso, localizada no município de Nova Olinda, os moradores entrevistados afirmaram ter conhecimento sobre reciclagem, mas que nesta comunidade não possuem reciclagem de resíduos e não conhecem nenhum catador ou pessoa que trabalhe com estes materiais. Apenas uma pessoa afirmou fazer a separação de lixo.

$\mathrm{Na}$ visita à comunidade do Sertãozinho, localizada na cidade do Crato, os moradores que foram entrevistados disseram não possuir água encanada. O número de pessoas que têm e que não têm conhecimento sobre reciclagem ficou igualado e nenhum dos entrevistados conhece catadores ou pessoas que trabalham com reciclagem na localidade e que apenas uma pessoa faz separação de lixo, dentre todos os entrevistados.

Com base nos resultados apresentados, nota-se que a coleta seletiva e a logística reversa são assuntos pouco abordados pelos moradores. Para Machado, Feres e Gonçalves (2019), a logística reversa (LR) é definida como a área responsável pela reutilização de materiais e produtos, buscando reintegrá-los a processos produtivos sustentáveis.

A reciclagem pode trazer um grande impacto no turismo e na geração de renda nas localidades onde é praticado. Segundo a BRK Ambiental (2019), são exemplos disto, Áustria, Alemanha, Bélgica e Holanda, lugares que reciclam $50 \%$ do lixo produzido.

Além da criação de empregos e a geração de renda, a reciclagem pode aumentar a qualidade de vida das pessoas e diminuir a quantidade de resíduos enviados para os depósitos de lixo e aterros sanitários, prolongando a vida útil desses locais. Desta forma, é notório os benefícios ocasionados pela coleta seletiva, 
contribuindo na redução de poluição, no desenvolvimento da cidade e na melhoria da economia. Assim, é fundamental o papel da comunidade para o sucesso desse processo.

O Quadro 3 apresenta dificuldades encontradas nas comunidades e sugestões para as mesmas.

Quadro 3 - Dificuldades e sugestões

\begin{tabular}{|c|c|c|c|}
\hline COMUNIDADE & CIDADE & DIFICULDADES & SOLUÇŐES \\
\hline Caldas & Barbalha & $\begin{array}{l}\text { Desconhecimento da existência de } \\
\text { programas na comunidade voltados } \\
\text { para questões ambientais. }\end{array}$ & $\begin{array}{l}\text { Medidas educativas relacionadas aos } \\
\text { assuntos envolvendo o meio ambiente. }\end{array}$ \\
\hline Pedra Branca & Nova Olinda & $\begin{array}{l}\text { Lixo deixado por turistas; ausência } \\
\text { de ponto de reciclagem e caçambas } \\
\text { de lixos nas ruas da comunidade; } \\
\text { inexistência de catadores. }\end{array}$ & $\begin{array}{l}\text { Placas de conscientização e caçambas de } \\
\text { lixo nas ruas e nos pontos turísticas. } \\
\text { Incentivo nas práticas de catação de lixo } \\
\text { para as famílias mais carentes a fim de } \\
\text { gerar renda. }\end{array}$ \\
\hline Sertãozinho & Nova Olinda & $\begin{array}{l}\text { Inexistência de catadores; } \\
\text { desconhecimento da metade dos } \\
\text { entrevistados sobre reciclagem; e } \\
\text { uma quantidade mínima de } \\
\text { moradores faz a separação de lixo. }\end{array}$ & $\begin{array}{l}\text { Incentivo nas práticas de catação de lixo } \\
\text { para as famílias mais carentes a fim de } \\
\text { gerar renda. Medidas educativas } \\
\text { relacionadas a reciclagem e separação de } \\
\text { lixo. }\end{array}$ \\
\hline Sitio Gostoso & Crato & $\begin{array}{l}\text { Inexistência de reciclagem e } \\
\text { catadores; e uma quantidade } \\
\text { mínima de moradores faz a } \\
\text { separação de lixo. }\end{array}$ & $\begin{array}{l}\text { Incentivo nas práticas de catação de lixo } \\
\text { para as famílias mais carentes a fim de } \\
\text { gerar renda. Medidas educativas } \\
\text { relacionadas a reciclagem e separação de } \\
\text { lixo. }\end{array}$ \\
\hline
\end{tabular}

Fonte: Os autores (2021)

\section{CONSIDERAÇÕES}

Os impactos negativos decorrentes da geração dos resíduos sólidos podem ser minimizados através de uma eficaz gestão dos resíduos. A gestão dos resíduos influencia na saúde, na qualidade de vida e no desenvolvimento das comunidades. Este trabalho teve como principal objetivo, apresentar resultados parciais do projeto, para a constituição de uma rede de coleta seletiva de resíduos sólidos.

Portanto, como resultados parciais obtidos através das visitas e entrevistas elaboradas, concluiu-se que os moradores das comunidades não entendem da tamanha importância da reciclagem e da separação de lixo e que pequenas atitudes realizadas diariamente fazem total diferença no meio ambiente, além de melhorar a saúde humana e a imagem do local. 
Sendo assim, seria ideal um trabalho na prática com o ODS 8 - Trabalho Descente e Crescimento Econômico, ODS 11 - Cidades e Comunidades Sustentáveis e ODS 13 - Ação contra a mudança Global do Clima. Tendo em vista que, transformar a gestão dos moradores das comunidades é essencial para que o desenvolvimento sustentável seja alcançado.

Sugere-se a princípio uma capacitação com as comunidades dos geossítios, por meio de cursos e oficinas relacionados à educação ambiental, saúde, economia e empreendedorismo, para que seja possível a logística reversa dos resíduos encontrados no Território do Araripe Geopark mundial da UNESCO.

O lixo produzido por atividades humanas já é considerado um problema mundial. Portanto, uma conscientização a respeito do consumo é de extrema importância, visto que, o reaproveitamento, a reciclagem e o descarte adequado dos resíduos sólidos são práticas essenciais para que se construa uma sociedade sustentável. A reciclagem promove a criação de empregos sustentáveis e diminui o impacto negativo no meio ambiente que são causados pelo descarte incorreto dos resíduos e pela falta de conhecimento das pessoas.

Ações como descarte adequado e apoiar cooperativas de catadores e reciclagem, podem ser realizadas nas próprias comunidades. A prática da reciclagem, da coleta seletiva e da logística reversa tem impacto também na formação das futuras gerações, pois é de grande importância que as crianças aprendem novos hábitos a fim de melhorar o meio ambiente da sua própria comunidade. Dessa forma, investir em ações que promovam uma mudança de hábitos dentro das comunidades é essencial.

Como por exemplo, instruir que a cada $50 \mathrm{~kg}$ de alumínio usado e reciclado evitaria a extração de 5.000 kg de minério, e geraria renda e empregos para usuários de programas, mantendo a comunidade sempre limpa. Além dos cursos, serão ofertadas oficinas de preparação para o associativismo e cooperativismo, e oficinas para a criação de geoprodutos a serem desenvolvidos com os resíduos.

O trabalho possui uma contribuição acadêmica importante, pois caracterizou e diagnosticou a importância para a comunidade estudada o reaproveitamento e reciclagem dos resíduos, garantindo sustentabilidade e possibilidade de surgimento 
futuro de empreendimentos com base na economia criativa conforme experiências relatadas na literatura científica.

A contribuição social está presente, pois o trabalho buscou ser o primeiro passo como incentivo ao surgimento de empreendimentos sustentáveis. O trabalho assim responde à questão de pesquisa colocadas e atinge seus principais objetivos expressos no corpo do trabalho.

Para pesquisas futuras sugerem-se o acompanhamento das ações desenvolvidas pela comunidade, e a coleta e análise dos dados obtidos. Identificação de resultados positivos e ou negativos quanto ao estabelecimento de ações sustentáveis. Sugere-se, ainda um trabalho que busque criar um modelo matemático que quantifique os resíduos produzidos.

\section{REFERÊNCIAS}

BARBOSA, M.R; COSTA, I; GONÇALVES, R.F. Uma proposta de funcionalidades para sistemas de informação dedicados à logística reversa. São Paulo, 2015.

BELLEN, H. M. V; PETRASSI, A. C. A. Gerenciamento de resíduos: uma reflexão a partir dos objetivos de desenvolvimento sustentável. Rio de janeiro, 2017.

BRASIL. Lei no 12.305, de 2 de agosto de 2010. Institui a Política Nacional de Resíduos Sólidos; altera a Lei no 9.605, de 12 de fevereiro de 1998; e dá outras providências. Disponível em: http://www.planalto.gov.br/ccivil 03/ ato20072010/2010/lei/l12305.htm. Acesso em: abr. 2021.

BRAVO, Thamara Lins; PEÇANHA, Anderson Lopes, WERNER, Elias Terra; SANTOS, Alexandre Augusto Oliveira. Educação ambiental e percepção da implantação de coleta seletiva de lixo urbano em De Alegre, ES. Revista gestão e Sustentabilidade Ambiental. Florianópolis, v. 7, n. 1, p. 375-396, jan./mar. 2018.

https://doi.org/10.19177/rgsa.v7e12018375-396

COMO DESTINAÇÃO correta do lixo pode contribuir para preservação do meio ambiente? Revista Brasil, 2021. Disponível em: https://radios.ebc.com.br/revista-brasil/2021/06/comodestinacao-correta-do-lixo-domestico-pode. Acesso em: ago. 2021.

CONHEÇA AS ODS. CNM, 2020. Disponível em: https://ods.cnm.org.br/agenda-2030. Acesso em: abr. 2021.

CONKE, Leonardo Silveira; NASCIMENTO, Elimar Pinheiro do. A coleta seletiva nas pesquisas brasileiras: uma avaliação metodológica. Revista Brasileira de Gestão Urbana (Brazilian Journal of Urban Management). DF, Brasil, 2018. https://doi.org/10.1590/21753369.010.001.a014 
DESCARTE INCORRETO de lixo: entenda por que é preciso mudar esse cenário no país. BRK Ambiental, 2021. Disponível em: https://blog.brkambiental.com.br/descarte-de-lixo-2/. Acesso em: maio 2021.

DESTINAÇÃO inadequada de lixo cresce 16\% em uma década. Agência Brasil, 2020. Disponível em: https://agenciabrasil-ebc-combr.cdn.ampproject.org/c/s/agenciabrasil.ebc.com.br/saude/noticia/2020-12/destinacaoinadequada-de-lixo-cresce-16-em-uma-decada?amp . Acesso em: ago. 2021.

FAXINA, F. Environmental sustainability in fishing communities within tourist destinations: the case of Mem de Sá Island - Brazil. Revista de Gestão Ambiental e Sustentabilidade GeAS. J. Environ. Manag. \& Sust. v.10, n. 10, p. 1-20, e16311, 2021. https://doi.org/10.5585/geas.v10i1.16311

GARCIA, M. B. S. et al. Resíduos sólidos: responsabilidade compartilhada. Rio de Janeiro, 2015. https://doi.org/10.15202/1981996X.2015v9n2p77

GUIA completo da gestão de resíduos sólidos. VG Resíduos, 2020. Disponível em: https://www.vgresiduos.com.br/blog/guia-completo-da-gestao-de-residuos-solidos/ . Acesso em: ago. 2021.

IMPACTOS da má gestão dos resíduos sólidos. VG Resíduos, 2020. Disponível em: https://www.vgresiduos.com.br/blog/impactos-da-ma-gestao-dos-residuos-solidos/. Acesso em: ago. 2021.

MACHADO, Gabriel Cappello; FERES, Pedro Pereira; GONÇALVES, Max Filipe Silva. Reverse logistics: feasibility analysis of the collection and restitution of lubricating oil used or contaminated. Journal Of Engineering And Technology For Industrial Applications, v. 5, p. 62-67, mar. 2019. https://doi.org/10.5935/2447-0228.20190009

MARGETA, J. Selection and evaluation of a septage management concept for islands: The case study of Bra c c Island. Journal of Environmental Management, n. 285, 112128, 2021. https://doi.org/10.1016/j.jenvman.2021.112128

MAIS de $50 \%$ das cidades brasileiros descartam o lixo de modo incorreto. Retec Resíduos, 2019. Disponível em: https://retecresiduos.com.br/mais-de-50-das-cidades-brasileirosdescartam-o-lixo-de-modo-incorreto/. Acesso em: maio 2021.

MENDES, Giselly S. et al. Logística reversa: estudo de caso em uma indústria de artefatos plásticos. Exacta, v. 14. São Paulo, 2016. https://doi.org/10.5585/exactaep.v14n1.6110

POR QUE as latas de lixo são separadas por cor? Koleta Ambiental, 2019. Disponível em: https://www.koleta.com.br/post/por-que-as-latas-de-lixo-s\%C3\%A3o-separadas-por-cor. Acesso em: ago. 2021.

OS 17 OBJETIVOS de Desenvolvimento Sustentável. Agenda 2030, 2020. Disponível em: http://www.agenda2030.org.br/ods/13/. Acesso em: abr. 2021.

RIBEIRO, M. S. R. et al. Coleta seletiva: influência nos hábitos de descarte da população em Lavras, Minas Gerais. Minas Gerais, 2017. 
QUAL A IMPORTÂNCIA da reciclagem para uma sociedade mais sustentável? BRK ambiental, 2019. Disponível em: https://blog.brkambiental.com.br/reciclagem/. Acesso em: abr. 2021.

RODRIGUEZ, C. et al. Socioeconomic Profile of Tourists with a Greater Circular Attitude and Behaviour in Hotels of a Sun and Beach Destination. International Journal of Environmental Research and Public Health, v. 17, 9392, 2020. https://doi.org/10.3390/ijerph17249392

SCHUINSEKEL, Éder O. et al. Logística reversa de resíduos de equipamentos eletroeletrônicos e seus reflexos ao meio ambiente. URI, RS, 2017.

SILVA, W.B. et al. A importância da logística reversa no âmbito organizacional e suas contribuições com ênfase na responsabilidade ambiental: uma análise bibliográfica.

Encontro de Extensão, Docência e Iniciação Científica (EEDIC), v. 6, nov. 2019.

SOUZA, M. C. B. M; MELLO I.S. Resíduos sólidos: coleta seletiva estímulo para o aumento da reciclagem e melhoria de renda dos catadores. Revista Eletrônica Gestão \& Saúde, v.6, n.3, 2015. https://doi.org/10.18673/gs.v6i3.22425

TSAI, M. F. et al. Sustainable solid-waste management in coastal and marine tourism cities in Vietnam: A hierarchical-level approach. Resources, Conservation \& Recycling 168, 105266, 2021. https://doi.org/10.1016/j.resconrec.2020.105266

WANG, L. E. et al. Exploring the patterns of food waste generation by tourists in a popular destination. Journal of Cleaner Production, n. 279, 123890, 2021.

https://doi.org/10.1016/j.jclepro.2020.123890

YIN, R. K. Estudo de caso: planejamento e métodos. 5. ed. Porto Alegre: Bookman, 2015.

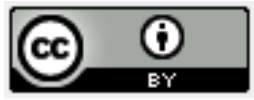

Artigo recebido em: 01/06/2021 e aceito para publicação em: 09/09/2021

DOI:https://doi.org/10.14488/1676-1901.v21i3.4349 